\title{
Water and sugar-sweetened beverage consumption and changes in BMI among Brazilian fourth graders after 1-year follow-up
}

\author{
Rosely Sichieri ${ }^{1, *}$, Edna M Yokoo ${ }^{2}$, Rosangela A Pereira ${ }^{3}$ and Glória V Veiga ${ }^{3}$ \\ ${ }^{1}$ Department of Epidemiology, Institute of Social Medicine, State University of Rio de Janeiro, Rua São Francisco \\ Xavier 524, $7^{\circ}$ andar, Bloco E, CEP 20550-012 Rio de Janeiro, Brazil: ${ }^{2}$ Department of Epidemiology and \\ Biostatistics, Federal Fluminense University, Niterói, Rio de Janeiro, Brazil: ${ }^{3}$ Institute of Nutrition, Federal \\ University of Rio de Janeiro, Rio de Janeiro, Brazil
}

Submitted 1 April 2011: Final revision received 15 December 2011: Accepted 24 February 2012: First published online 28 May 2012

\begin{abstract}
Objective: We examined whether drinking water per se is associated with drinking less of other beverages and whether changes in BMI are associated with the intake of water and other beverages.

Design: Secondary analysis of a randomized trial of fourth graders followed over 1 year.

Setting: Public schools in the metropolitan area of Rio de Janeiro, Brazil.

Subjects: Participants were 1134 students aged 10-11 years.

Results: At baseline, a higher frequency of water consumption was associated with a greater daily intake of fruit juice $(P=0 \cdot 02)$ and a higher daily frequency of milk $(P=0 \cdot 005)$. In the intervention group, the baseline frequency of water consumption was negatively associated with weight change over 1 year but without statistical significance (coefficient $=-0 \cdot 08 \mathrm{~kg} / \mathrm{m}^{2} ; 95 \%$ CI $-0 \cdot 37$, $0 \cdot 24 \mathrm{~kg} / \mathrm{m}^{2}$ ), whereas fruit juice intake frequency was positively associated with weight change: each increase in fruit juice intake of 1 glass/d was associated with a BMI increase of $0 \cdot 16(95 \%$ CI $0 \cdot 02,0 \cdot 30) \mathrm{kg} / \mathrm{m}^{2}$.

Conclusions: Our findings do not support a protective effect of water consumption on BMI, but confirm consumption of juice drinks as a risk factor for BMI gain. Students who reported high water consumption also reported high intake of other beverages; therefore, the promotion of water consumption per se would not prevent excessive weight gain.
\end{abstract}

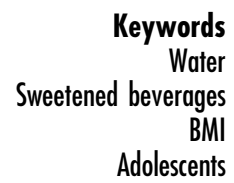

words

rages

Adolescents
Increased consumption of water is believed to trigger biochemical mechanisms that enhance weight loss ${ }^{(1,2)}$. However, experimental designs where sugar-sweetened beverages (SSB) have been replaced with water have yielded controversial findings ${ }^{(3-7)}$.

Systematic reviews, primarily of observational studies, compared the effects of drinking water and other beverages on energy intake and concluded that water plays an important role in reducing energy intake ${ }^{(8,9)}$. These findings have stimulated heavy marketing by the beverage industry of the importance of high levels of fluid consumption, a recommendation that has been well received by nutritionists and other health professionals, but which lacks strong scientific basis. In addition, the fluid sources that are being marketed include not only plain water, but also high-energy beverages ${ }^{(10,11)}$. There is no evidence that people require large intakes of liquids, as pointed out in the most recent Dietary Guidelines for Americans ${ }^{(12)}$ and in the Brazilian guidelines, which recommend drinking 6 to 8 glasses of water daily, mainly in between meals ${ }^{(13)}$.

The hydration issue sets a fundamental question for public health policy: is drinking water per se associated with drinking less of other beverages? To address this question, we analysed the association of the frequency of water consumption with the frequency of consumption and the amount consumed of other beverages. We also tested whether the frequencies of water, soda and juice consumption at baseline were associated with BMI change over one school year in an intervention study with a large sample of fourth grade students.

\section{Methods}

The present paper is a secondary analysis of a randomized school trial of fourth graders from twenty-two public schools in the city of Niterói, located in the 
metropolitan area of Rio de Janeiro, Brazil. The study was conducted in 2005. Niterói has approximately 450000 inhabitants, and most fourth graders are between 10 and 11 years old. The sample included forty-seven classes from twenty-two schools. The details of and results from that study may be found elsewhere ${ }^{(6)}$. In brief, the intervention in half of the schools included a nutritional programme administered over one school year that focused on reducing the consumption of sodas. The control group intervention included two one-hour sessions on general health issues and common advice on healthy diets. The main outcome measured was BMI. The results showed that after the intervention, BMI decreased only in overweight/obese girls from the intervention group; no changes were observed in the control group.

Beverage intakes at baseline were measured through a drinking frequency questionnaire and one $24 \mathrm{~h}$ recall. After the $24 \mathrm{~h}$ recall, children were asked to record their usual frequency of soda, juice and milk consumption. The drinking frequency questionnaire included items on sodas (colas and other sodas), guaraná natural (a typical Brazilian non-carbonated SSB), natural and industrialized fruit juices, and milk. The eight possible answers ranged from 'never or almost never' to ' 3 or more times per day'. Water intake was evaluated by asking for the usual number of glasses consumed daily (from 'zero or never drink water' to ' 7 or more glasses per day'). Baseline data were collected during the summer months in the southern hemisphere (February and March). For data analysis, all frequency of consumption values ranged from 0 to 8 .

The measured outcome was $(\mathrm{BMI}=[$ weight $(\mathrm{kg})] /$ $\left[(\text { height }(\mathrm{m})]^{2}\right)$. Anthropometric measurements were taken at the beginning and at the end of the school year. Height (without shoes) was measured to the nearest centimetre using a portable stadiometer (Seca). Weight (in light clothing) was measured to the nearest $0 \cdot 1 \mathrm{~kg}$ on portable scales (Tanita). The classification of nutritional status was based on the BMI $Z$-score categories proposed by the $\mathrm{WHO}^{(14)}$.
Co-variables related to BMI and beverage consumption included practising recreational physical activities (yes/no), having physical activity classes at school (yes/no) and screen time (computer and television) in hours per day.

\section{Statistical analysis}

The data were analysed using the SAS statistical software package version $9 \cdot 2$ (SAS Institute Inc., Cary, NC, USA). Linear regression analysis was used to assess differences in BMI from baseline using the 'surveyreg' procedure, accounting for the cluster sample design (classes). The baseline frequency of water consumption and the amount and daily frequency of consumption of other beverages were contrasted with BMI at baseline and change in BMI after the intervention, in both intervention and control schools.

\section{Results}

A total of 1134 students participated in the study. There was no difference in the mean number of glasses of water consumed daily by sex ( $5 \cdot 6$ glasses/d among boys, $5 \cdot 5$ glasses/d among girls). Similar results were found for other beverages, except for the mean daily frequency of guaraná consumption, which was slightly higher among boys than among girls $(0.5$ v. 0.4 glasses/d, $P=0.02$; Table 1$)$. Data from the $24 \mathrm{~h}$ recall indicated that the amount $(\mathrm{ml} / \mathrm{d})$ of soda consumption was greater than that of fruit juice, with soda consumption almost threefold higher than juice consumption for both sexes (Table 1).

The average water intake (glasses/d) according to sex and nutritional status is summarized in Table 2 . There was a positive linear trend in water intake according to BMI category, mainly due to the smaller intake among the underweight group, although borderline statistical significance using linear $\chi^{2}$ tests was found in both sexes ( $P=0.06$ among boys, $P=0.08$ among girls).

Table 3 illustrates the daily frequency of beverage consumption (glasses/d) and the amount $(\mathrm{ml} / \mathrm{d})$ of soda

Table 1 Means with their standard errors for the daily frequency of drinking water and other beverages ${ }^{*}$ and for the amount of soda and fruit juice intaket: fourth grade students aged 10-11 years, Rio de Janeiro, Brazil

\begin{tabular}{|c|c|c|c|c|c|c|c|}
\hline & \multicolumn{3}{|c|}{ Boys } & \multicolumn{3}{|c|}{ Girls } & \multirow[b]{2}{*}{$P$} \\
\hline & $n$ & Mean & SE & $n$ & Mean & SE & \\
\hline \multicolumn{8}{|c|}{ Frequency (glasses/d) } \\
\hline Water & 459 & $5 \cdot 6$ & $0 \cdot 10$ & 517 & $5 \cdot 5$ & $0 \cdot 10$ & 0.67 \\
\hline Sodas & 454 & 0.6 & 0.04 & 515 & 0.6 & 0.04 & 0.55 \\
\hline Guaraná & 395 & 0.5 & 0.03 & 443 & 0.4 & 0.02 & 0.02 \\
\hline Fruit juice & 444 & $0 \cdot 8$ & 0.03 & 506 & $0 \cdot 8$ & 0.04 & 0.76 \\
\hline Milk & 440 & $1 \cdot 2$ & 0.04 & 515 & $1 \cdot 0$ & 0.03 & 0.06 \\
\hline \multicolumn{8}{|c|}{ Amount (ml/d) } \\
\hline Sodas & 535 & 240 & 20 & 599 & 260 & 19 & 0.45 \\
\hline Fruit juice & 535 & 83 & 9 & 599 & 98 & 10 & 0.29 \\
\hline
\end{tabular}

*Based on a drinking frequency questionnaire.

tBased on $24 \mathrm{~h}$ recall. 
Table 2 Mean and standard deviation of water intake according to sex and BMI category: fourth grade students aged 10-11 years, Rio de Janeiro, Brazil

\begin{tabular}{|c|c|c|c|c|c|c|c|c|}
\hline & \multicolumn{4}{|c|}{ Boys } & \multicolumn{4}{|c|}{ Girls } \\
\hline & \multirow[b]{2}{*}{$n$} & \multirow[b]{2}{*}{$\%$} & \multicolumn{2}{|c|}{ Glasses of water/d } & \multirow[b]{2}{*}{$n$} & \multirow[b]{2}{*}{$\%$} & \multicolumn{2}{|c|}{ Glasses of water/d } \\
\hline & & & Mean & SD & & & Mean & SD \\
\hline Underweight & 8 & $1 \cdot 7$ & $5 \cdot 1$ & 1.9 & 6 & $1 \cdot 2$ & $4 \cdot 8$ & $1 \cdot 7$ \\
\hline Normal weight & 311 & $67 \cdot 7$ & $5 \cdot 5$ & 1.9 & 356 & $69 \cdot 3$ & $5 \cdot 5$ & 1.9 \\
\hline Overweight & 83 & $18 \cdot 3$ & $5 \cdot 8$ & $2 \cdot 0$ & 102 & $19 \cdot 2$ & $5 \cdot 7$ & 1.9 \\
\hline Obese & 57 & $12 \cdot 3$ & $5 \cdot 9$ & $2 \cdot 1$ & 53 & $10 \cdot 3$ & $5 \cdot 7$ & $1 \cdot 5$ \\
\hline
\end{tabular}

Table 3 Daily mean frequency of beverage consumption, mean amount of soda and juice intake and mean BMI according to the number of glasses of water consumed daily: fourth grade students aged 10-11 years, Rio de Janeiro, Brazil

\begin{tabular}{lccc}
\hline & $\begin{array}{c}\leq 3 \text { glasses } \\
\text { water/d }\end{array}$ & $\begin{array}{c}>3 \text { glasses } \\
\text { water/d }\end{array}$ & $P$ \\
\hline $\begin{array}{l}\text { Daily mean frequency of } \\
\text { intake }\end{array}$ & & & \\
$\quad$ Sodas & 0.74 & 0.60 & 0.17 \\
$\quad$ Guaraná & 0.45 & 0.45 & 0.64 \\
$\quad$ Fruit juice & 0.72 & 0.83 & 0.11 \\
$\quad$ Milk & 1.02 & 1.20 & 0.005 \\
Mean amount $(\mathrm{ml} / \mathrm{d})$ & & & \\
$\quad$ Sodas & 274 & 291 & 0.07 \\
$\quad$ Fruit juice & 83 & 110 & 0.02 \\
Mean BMl $\left(\mathrm{kg} / \mathrm{m}^{2}\right)$ & 17.9 & 18.4 & 0.05 \\
\hline
\end{tabular}

and fruit juice consumption according to two categories of water consumption: $\leq 3$ glasses/d and $>3$ glasses $/ \mathrm{d}$. Students in the group that drank $>3$ glasses water/d presented higher daily frequencies of fruit juice and milk consumption than the group that reported drinking $\leq 3$ glasses water/d, with a significance difference for milk intake $(P=0 \cdot 005)$. Additionally, the amounts of fruit juice and sodas consumed were higher in the group that reported drinking $>3$ glasses water/d with statistical significance only for fruit juice $(P=0 \cdot 02)$. Furthermore, the average BMI among children who drank $>3$ glasses water/d was slightly higher than in the group that drank $\leq 3$ glasses water $/ \mathrm{d}\left(18 \cdot 4 v .17 \cdot 9 \mathrm{~kg} / \mathrm{m}^{2} ; P=0 \cdot 05\right)$.

The overall changes in BMI $\left(\mathrm{kg} / \mathrm{m}^{2}\right)$ as a function of the type of beverage consumed are presented in Table 4 . The coefficients of the adjusted linear regression model controlled for age and sex showed an inverse association between water consumption and change in BMI, considering water consumption both as a continuous variable and a dichotomous variable ( $>3$ glasses/d, $\leq 3$ glasses/d). A significant association was observed only for categorical analysis (regression coefficient $=-0 \cdot 20 ; 95 \% \mathrm{CI}$ $-0 \cdot 40,-0 \cdot 004 ; P=0 \cdot 04)$. On the other hand, positive associations were found between the frequency of consumption of beverages containing added sugar (soda and juice) and the change in BMI when adjusted for age and sex. The model controlled for age, sex, physical activity, intervention and mutually adjusted showed similar effects for the change in BMI: an inverse association for water intake (number of glasses dichotomized; regression coefficient $=-0 \cdot 21 ; 95 \% \mathrm{CI}-0 \cdot 41,-0 \cdot 01 ; P=0 \cdot 04)$ and a positive association for daily frequency of fruit juice consumption (regression coefficient $=0 \cdot 15$; $95 \%$ CI $0 \cdot 1$, $0 \cdot 2 ; P=0 \cdot 002 ;$ Table 4). There was no dose effect on the change in BMI when the number of glasses of water consumed daily was categorized in tertiles (data not shown).

The fully adjusted model stratified for intervention and control schools presented the same tendency of a positive association for daily frequency of juice consumption and an inverse association for water intake, which was statistically significant only for control schools (regression coefficient $=-0 \cdot 31 ; 95 \% \mathrm{CI}-0 \cdot 57,-0 \cdot 05 ; P=0 \cdot 03)$.

\section{Discussion}

First, our findings indicate that students who drank $>3$ glasses water/d at baseline had a smaller incremental change in BMI than those who reported drinking $\leq 3$ glasses/d. This association has been shown in experimental studies ${ }^{(8,15)}$, suggesting that consuming more water may play a role in the prevention of weight gain. Stookey et al. ${ }^{(15)}$ observed a robust effect of water drinking on weight loss. An increase in drinking water to $\geq 1 \cdot 0 \mathrm{l} / \mathrm{d}$ was associated with a weight loss of approximately $2 \mathrm{~kg}$ over 12 months, independent of sociodemographic variables, food intake characteristics, energy intake and physical activity.

Second, stratifying the linear model analysis for intervention and control groups, an approach to fully control for changes associated with the intervention, showed that changes associated with BMI remained inverse for the intake of water but statistical significance was observed only among control schools. Therefore our data do not support the hypothesis that an increased intake of water would have a protective effect on weight gain.

That the association between water intake at baseline and change in BMI was observed only in the control group possibly indicates that small changes in the intervention 
Table 4 Change in BMI $\left(\mathrm{kg} / \mathrm{m}^{2}\right)$ according to consumption of sugar-sweetened beverages and water at baseline: fourth grade students aged $10-11$ years, Rio de Janeiro, Brazil

\begin{tabular}{|c|c|c|}
\hline & Regression coefficient & $95 \% \mathrm{Cl}$ \\
\hline \multicolumn{3}{|l|}{ Adjusted for age and sex } \\
\hline Glasses of water/d (continuous variable: 0 to 7 and more) & -0.03 & $-0.01,0.07$ \\
\hline Glasses of water/d (dichotomous variable: $>3 v . \leq 3$ ) & $-0 \cdot 20$ & $-0.40,-0.004$ \\
\hline Fruit juice (continuous variable: daily frequency) & $0 \cdot 16$ & $0.08,0.24$ \\
\hline Soda (continuous variable: daily frequency) & $0 \cdot 11$ & $0.03,0.25$ \\
\hline \multicolumn{3}{|c|}{ Adjusted for age, sex, physical activity, intervention and mutually adjusted } \\
\hline Glasses of water/d (dichotomous variable: $>3 v . \leq 3$ ) & $-0 \cdot 21$ & $-0.41,-0.01$ \\
\hline Fruit juice (continuous variable: daily frequency) & $0 \cdot 15$ & $0 \cdot 10,0 \cdot 20$ \\
\hline \multicolumn{3}{|l|}{ By intervention } \\
\hline \multicolumn{3}{|l|}{ Control schools } \\
\hline Glasses of water/d (dichotomous variable: $>3 v . \leq 3$ ) & -0.31 & $-0.57,-0.05$ \\
\hline Fruit juice (continuous variable: daily frequency) & $0 \cdot 12$ & $-0 \cdot 10,0 \cdot 25$ \\
\hline \multicolumn{3}{|l|}{ Intervention schools } \\
\hline Glasses of water/d (dichotomous variable: $>3 v$. $\leq 3$ ) & -0.08 & $-0 \cdot 37,0.24$ \\
\hline Fruit juice (continuous variable: daily frequency) & $0 \cdot 16$ & $0 \cdot 02,0.30$ \\
\hline
\end{tabular}

period masked the possible association in the intervention group, which was stimulated to drinking more water. It is possible that those classified in the high level of water intake at baseline would not have room for more change whereas those with low intake of water at baseline may have added more, blurring possible differences in intake during follow-up.

Additionally, the consumption of $>5$ glasses water/d (the third tertile of water intake) was not associated with a larger reduction in BMI gain compared with the intermediate tertile at follow-up, also indicating that these results do not support the hypothesis that a greater intake of water protects against weight gain.

Physical activity is a potential confounding factor in the association of water drinking and weight change because greater physical activity is associated with greater beverage drinking. However, we found that the effect of water consumption was the same after adjustment for recreational physical activity, physical activity at school and screen time, with the BMI changing by approximately $0.5 \mathrm{~kg} / \mathrm{m}^{2}$ when the group that drank $>3$ glasses/d was compared with the group that drank $\leq 3$ glasses/d.

Wang et al. ${ }^{(16)}$ estimated the impact of substituting water for SSB on energy intake among children and adolescents and found that this exchange decreased average total energy intake by $983 \mathrm{~kJ} / \mathrm{d}(235 \mathrm{kcal} / \mathrm{d})$. However, our baseline data indicated a positive association between the intake of water and other beverages; thus, children who reported to drink more water also had high consumption of other beverages and the observed effect of water consumption on the BMI change after the intervention probably was not due to the substitution of SSB.

Our findings are also consistent with many studies showing that SSB, particularly fruit juices, are a risk factor for weight gain. An increased intake of 1 glass fruit juice/d was associated with a $0 \cdot 16 \mathrm{~kg} / \mathrm{m}^{2}$ greater BMI. Daily frequency of fruit juice intake in the present study was slightly higher than soda intake among both boys and girls; as discussed in the previous analysis of the randomized trial, juices are an important source of sugar intake in Brazil ${ }^{(6)}$.

The most direct mechanism to explain the observed link between SSB consumption and obesity is the higher total energy intake associated with $\mathrm{SSB}^{(17)}$. A meta-analysis of eighty-eight studies found clear associations between SSB consumption, increased energy intake and body weight. It is interesting to note that studies funded by the food industry reported significantly smaller effects on energy intake than did non-industry-funded studies ${ }^{(18)}$. Another meta-analysis funded by the beverage industry showed no association between SSB consumption and BMI in children and adolescents ${ }^{(19)}$. However, Malik et al. argued that such results were found due to analytical errors, mainly because SSB consumption units were mixed up in the different studies selected $^{(20)}$.

The main finding of the current study is that the students who reported high consumption of plain water also had high consumption other beverages, including SSB and milk. Therefore, the study did not confirm the hypothesis that drinking water is associated with drinking less of other beverages. This finding can be translated into a clear recommendation that increasing water intake should be combined with the reduction in SSB consumption. This is a central topic in public health policy because beverage advertising encourages the intake of bottled and artificially flavoured waters as an innocuous (or even healthy) non-energy beverage and there is a common sense that all kinds of beverages can hydrate in the same way, including SSB and sports drinks.

Furthermore, a meta-analysis of energy intake over the course of a meal subsequent to the consumption of $\mathrm{SSB}^{(18)}$ suggested that food energy intake is higher among individuals with greater SSB intake. Drinking at meals may facilitate the consumption of larger amounts of food ${ }^{(9)}$. This is a possible explanation for our baseline data showing a borderline association between water consumption and BMI, because water consumption was also associated 
with SSB. Therefore, for a clear public health approach, the promotion of water consumption should be done together with a message of reducing the consumption of SSB in order to prevent weight gain in adolescents.

\section{Acknowledgements}

This research was funded by a grant from the Brazilian National Research Institute (CNPq) and by a scholarship from the Foundation of Research from Rio de Janeiro State (FAPERJ). There are no conflicts of interest. R.S. was the principal investigator, led the research project and participated in all phases of the study and manuscript preparation. G.V.V. was co-investigator of the project and participated in conceptualization of the intervention and collaborated in manuscript preparation. E.M.Y. and R.A.P. participated in conceptualization of the manuscript, conducted the analysis and collaborated in manuscript preparation. All authors contributed to the critical revision of the manuscript. The authors thank all participants and schools involved in the study.

\section{References}

1. Mathai ML \& Weisinger RS (2009) Response to 'hydration increases cell metabolism'. Int J Obes (Lond) 33, 386.

2. Thornton SN (2009) Hydration increases cell metabolism. Int J Obes (Lond) 33, 385.

3. James J \& Kerr D (2005) Prevention of childhood obesity by reducing soft drinks. Int J Obes (Lond) 29, Suppl. 2, S54-S57.

4. Davy BM, Dennis EA, Dengo AL et al. (2008) Water consumption reduces energy intake at a breakfast meal in obese older adults. J Am Diet Assoc 108, 1236-1239.

5. Muckelbauer R, Libuda L, Clausen K et al. (2009) Promotion and provision of drinking water in schools for overweight prevention: randomized, controlled cluster trial. Pediatrics 123, e661-e667.

6. Sichieri R, Trotte AP, De Souza RA et al. (2009) School randomised trial on prevention of excessive weight gain by discouraging students from drinking sodas. Public Health Nutr 12, 197-202.
7. Dennis EA, Dengo AL, Comber DL et al. (2010) Water consumption increases weight loss during a hypocaloric diet intervention in middle-aged and older adults. Obesity (Silver Spring) 18, 300-307.

8. Daniels MC \& Popkin BM (2010) Impact of water intake and weight status: a systematic review. Nutr Rev 68, 505-521.

9. Dennis EA, Flack KD \& Davy B (2009) Beverage consumption and adult weight management: a review. Eat Behav 10, 237-246.

10. Popkin BM, D'Anci KE \& Rosenbeg IH (2010) Water, hydration, and health. Nutr Rev 68, 439-458.

11. Popkin BM (2011) Contemporary nutritional transition: determinants of diet and its impact on body composition. Proc Nutr Soc 70, 82-91.

12. US Department of Agriculture \& US Department of Health and Human Services (2010) Report of the Dietary Guidelines Advisory Committee on the Dietary Guidelines for Americans. Washington, DC: USDA; available at http:// www.dietaryguidelines.gov

13. Brasil Coordenação Geral da Política de Alimentação e Nutrição, Secretaria de Atenção a Saúde, Ministério da Saúde (2006) Guia alimentar para a população brasileira: promovendo a alimentação saudável. Brasília: Ministério da Saúde.

14. De Onís M, Onyango AW, Borghi E et al. (2007) Development of a WHO growth reference for school-aged children and adolescents. Bull World Health Organ 85, 660-667.

15. Stookey JD, Constant F, Popkin BM et al. (2008) Drinking water is associated with weight loss in overweight dieting women independent of diet and activity. Obesity (Silver Spring) 16, 2481-2488.

16. Wang YC, Ludwig DS, Sonneville K et al. (2009) Impact of change in sweetened caloric beverage consumption on energy intake among children and adolescents. Arch Pediatr Adolesc Med 163, 336-343.

17. Olsen NJ \& Heitmann BL (2009) Intake of calorically sweetened beverages and obesity. Obes Rev 10, 68-75.

18. Vartanian LR, Schwartz MB \& Brownell KD (2007) Effects of soft drink consumption on nutrition and health: a systematic review and meta-analysis. Am J Public Health 97, 667-675.

19. Forshee RA, Anderson PA \& Storey ML (2008) Sugarsweetened beverages and body mass index in children and adolescents: a meta-analysis. Am J Clin Nutr 87, $1662-1671$.

20. Malik VS, Willett WC \& Hu FB (2009) Sugar-sweetened beverages and BMI in children and adolescents: reanalyses of a meta-analysis. Am J Clin Nutr 89, 438-439. 